See Article page e361.

\section{Commentary: Independent, additive or linked: A novel therapeutic option for the treatment of pulmonary hypertension may involve more than one mechanism}

James D. McCully, PhD, and

Ilias P. Doulamis, MD, $\mathrm{PhD}$

Mitochondrial transplantation is a novel methodology that uses intact, respiration-competent mitochondria isolated from the patient's own body to augment or enhance intrinsic mitochondrial function. ${ }^{1}$ Mitochondrial transplantation has been shown to be safe and efficacious in in vitro, small and large animal models for the treatment of myocardial ischemia/reperfusion injury. ${ }^{1,2}$ In this issue of the Journal, Hsu and colleagues ${ }^{3}$ extend these findings and demonstrate the efficacy of mitochondrial transplantation in a rodent model of pulmonary hypertension $(\mathrm{PH})$. The authors demonstrate that serial injections of syngeneic mitochondria upregulate proteins associated with the nonproliferative and contractile phenotype, attenuate pulmonary artery (PA) hyper-reactivity, and significantly reduce PA medial thickness. The authors also shown that mitochondrial transplantation significantly restores right ventricular (RV) remodeling by reducing RV mass and $\mathrm{RV}$ wall thickness.

Hsu and colleagues ${ }^{3}$ also introduce systemic (venous) delivery of mitochondria via the jugular vein. This route of delivery may be justified for delivery to the lungs but requires further analysis, as uptake and distribution were

\footnotetext{
From the Department of Cardiac Surgery, Boston Children's Hospital, and Department of Surgery, Harvard Medical School, Boston, Mass.

Disclosures: Dr McCully has patents pending for the isolation and usage of mitochondria and is a consultant with Cellvie Sciences Inc. Dr Doulamis reported no conflicts of interest.

The Journal policy requires editors and reviewers to disclose conflicts of interest and to decline handling or reviewing manuscripts for which they may have a conflict of interest. The editors and reviewers of this article have no conflicts of interest.

Received for publication Aug 14, 2020; revisions received Aug 14, 2020; accepted for publication Aug 17, 2020; available ahead of print Nov 4, 2021.

Address for reprints: James D. McCully, PhD, Department of Cardiac Surgery, Boston Children's Hospital, 300 Longwood Ave, Enders Building, Room 407, Boston, MA 02115 (E-mail: james_mccully@hms.harvard.edu).

J Thorac Cardiovasc Surg 2022;163:e375-6

$0022-5223 / \$ 36.00$

Copyright (c) 2020 by The American Association for Thoracic Surgery

https://doi.org/10.1016/j.jtcvs.2020.08.044
}

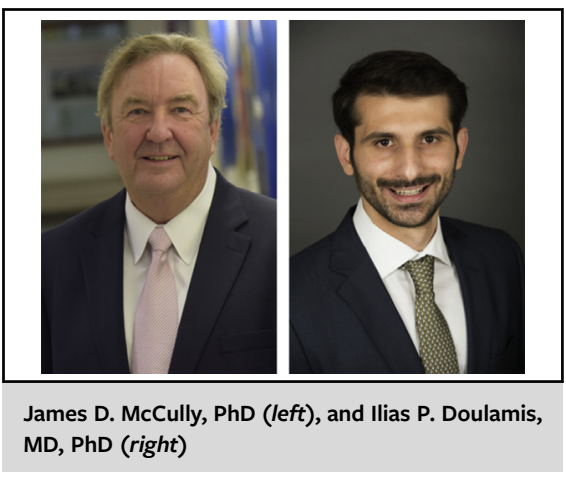

CENTRAL MESSAGE

Mitochondrial transplantation provides a novel therapeutic option for the treatment of pulmonary hypertension through enhanced vascular and right ventricular remodeling.

determined ex vivo and only in the lungs, and biodistribution to other organs, in particular the right ventricle, was not examined.

In our investigations, we have used either direct injection or arterial delivery of exogenous mitochondria via the coronary ostium to the coronary arteries, the PA to the lungs, and the infrarenal artery to the kidneys. ${ }^{4-6}$ Both routes of delivery have been shown to be safe and efficacious and have been shown by whole-body imaging to provide endorgan specific uptake in the heart, lung, and the kidney, respectively. ${ }^{4-6}$ The exogenous mitochondria were undetectable in any other organ. ${ }^{4-6}$

Hsu and colleagues ${ }^{3}$ demonstrate improved PA function with mitochondria transplantation and suggest this improves $\mathrm{RV}$ function. We would like to suggest that an alternative mechanism may be that the effects on RV function are independent of improved PA function and may be the result of endocardial uptake of mitochondria distributed to the RV following jugular vein delivery. The exogenous mitochondria in the RV would allow for enhanced RV function, in agreement with previous reports demonstrating improvement in ventricular function following exogenous mitochondrial delivery to the myocardium. ${ }^{1,2,4}$ Whether the effects of mitochondrial transplantation on $\mathrm{PH}$ are independent or additive or linked requires greater investigation, as delivery to either or both the PA and the RV may be required. 
We congratulate Hsu and colleagues ${ }^{3}$ for their excellent study, which adds a new therapeutic option for the treatment of PH.

\section{References}

1. McCully JD, Cowan DB, Emani SM, del Nido PJ. Mitochondrial transplantation: from animal models to clinical use in humans. Mitochondrion. 2017;32:127-34.

2. Emani SM, McCully JD. Mitochondrial transplantation: applications for pediatric patients with congenital heart disease. Transl Pediatr. 2018;7:169-75.

3. Hsu C-H, Roan J-N, Fang S-Y, Chiu M-H, Cheng T-T, Huang C-C, et al. Transplantation of viable mitochondria improves right ventricular performance and pulmonary artery remodeling in rats with pulmonary arterial hypertension. $J$ Thorac Cardiovasc Surg. 2022;163:e361-73.

4. Shin B, Saeed MY, Esch JJ, Guariento A, Blitzer D, Moskowitzova K, et al. Myocardial protection by intracoronary delivery of mitochondria: safety and efficacy in the ischemic myocardium. JACC Basic Transl Res. 2019;4:871-88.

5. Moskowitzova K, Orfany A, Liu K, Ramirez-Barbieri G, Thedsanamoorthy JK, Yao R, et al. Mitochondrial transplantation enhances murine lung viability and recovery after ischemia reperfusion injury. Am J Phys Lung Cell Mol Phys. 2020; 318:L78-88.

6. Doulamis IP, Guariento A, Duignan T, Kido T, Orfany A, Saeed MY, et al. Mitochondrial transplantation by intra-arterial injection for acute kidney injury. Am J Physiol Renal Physiol. 2020;319:F403-13.
See Article page e361.

\section{Commentary: Transplanting the powerhouse of the cell to enhance cardiopulmonary repair}

Vishnu Vasanthan, MD, Ali Fatehi Hassanabad, MD, MSc, and Paul W. M. Fedak, MD, PhD, FRCS(C)

Waitlist mortality for organ transplantation remains unacceptably high. ${ }^{1}$ Sustained efforts to address the limitations of donor organ availability have focused on transplanting donor cells - instead of whole organs - as restorative therapies for cardiovascular repairs. ${ }^{2}$ Despite the promise of cell therapies for cardiovascular diseases, clinical translation is challenged by substantial regulatory barriers and suboptimal efficacy in controlled clinical trials. ${ }^{3,4}$ After decades of investigation into mechanisms of benefit, we now understand that transplanted cells' beneficial effects are a consequence of paracrine actions of their secreted elements. ${ }^{5}$ Do we need entire organs and cells, or can we more simply reduce some directed therapies to their subcellular

From the Section of Cardiac Surgery, Department of Cardiac Sciences, Libin Cardiovascular Institute, Cumming School of Medicine, University of Calgary, Calgary, Alberta, Canada.

Disclosures: The authors reported no conflicts of interest.

The Journal policy requires editors and reviewers to disclose conflicts of interest and to decline handling or reviewing manuscripts for which they may have a conflict of interest. The editors and reviewers of this article have no conflicts of interest.

Received for publication Aug 31, 2020; revisions received Aug 31, 2020; accepted for publication Sept 1, 2020; available ahead of print Nov 15, 2021.

Address for reprints: Paul W. M. Fedak, MD, PhD, FRCS(C), Section of Cardiac Surgery, Department of Cardiac Sciences, Libin Cardiovascular Institute, Cumming School of Medicine, University of Calgary, C849, 1403-29 St, NW, Calgary, Alberta, T2N 2T9, Canada (E-mail: paul.fedak@gmail.com).

J Thorac Cardiovasc Surg 2022;163:e376-7

$0022-5223 / \$ 36.00$

Copyright (c) 2020 by The American Association for Thoracic Surgery

https://doi.org/10.1016/j.jtcvs.2020.09.007

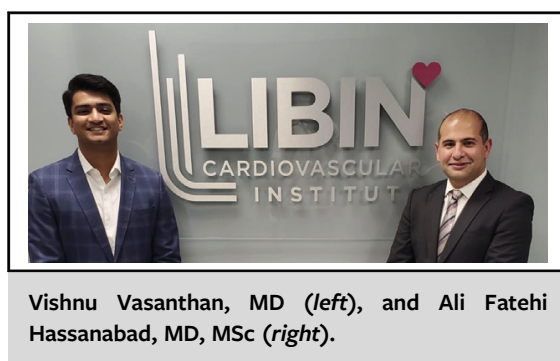

CENTRAL MESSAGE

Organelle transplantation using mitochondria shows potential to improve cardiopulmonary repair and performance after injury.

elements? Perhaps for some applications, cell therapy is a big idea that could be even smaller. We can leverage only the most critical fragments of cells as a viable therapy.

Mitochondria are the cells' powerhouse, the cellular engine that drives energy production and sustains healthy metabolism. Organelle transplantation using mitochondria is now a promising new frontier to reverse end-stage organ dysfunction in the face of excessive hemodynamic stress. Chronic pulmonary hypertension can cause irreparable damage to the pulmonary circulation and myocardium of the right ventricle. Contemporary pulmonary artery hypertension management can improve hemodynamics, but novel therapies are necessary to reverse maladaptive pulmonary artery remodeling to prevent disease progression and reduce 